\title{
TM4SF1 Regulates Pancreatic Cancer Migration and Invasion In Vitro and In Vivo
}

\author{
Jia Cao ${ }^{a}$ Jia-chun Yang ${ }^{a}$ Vijaya Ramachandran ${ }^{b}$ Thiruvengadam Arumugam ${ }^{b}$ \\ De-feng Deng ${ }^{b} \quad$ Zhao-shen Lic Lei-ming Xua Craig D. Logsdon ${ }^{b}$
}

aDepartment of Gastroenterology, Xinhua Hospital, Shanghai Jiaotong University School of Medicine, Shanghai, China; bepartment of Cancer Biology, The University of Texas MD Anderson Cancer Center, Houston, Texas, United States; 'Department of Gastroenterology, Changhai Hospital, the Second Military Medical University, Shanghai, China

\section{Key Words}

TM4SF1 • Invasion • Migration • Pancreatic cancer • Matrix metalloproteinase

\begin{abstract}
Background/Aims: The cell surface protein transmembrane 4 L6 family member 1 (TM4SF1) has been detected in various tumors and plays a major role in the development of cancer. We aimed to investigate the effects of TM4SF1 on the migration and invasion of pancreatic cancer in vitro and in vivo and explore its related molecular mechanisms. Methods: qRTPCR and immunohistochemical analyses were used to measure the expression of TM4SF1 in pancreatic cancer tissues and adjacent tissues. TM4SF1 was silenced using siRNA and shRNA to investigate the role of this protein in the proliferation and metastasis of pancreatic cancer cells. MTS and Transwell assays were used to examine the effect of TM4SF1 on pancreatic cancer cell lines. The expression and activity of MMP-2 and MMP-9 were determined by qRT$\mathrm{PCR}$, western blots and gelatin zymography. In vivo, orthotopic pancreatic tumor models were used to examine the formation of metastasis. Results: qRT-PCR and immunohistochemical analyses showed that TM4SF1 was highly expressed in pancreatic cancer tissues compared with the adjacent tissues. In in vitro experiments the silencing of TM4SF1 reduced cell migration and invasion and down-regulated the expression and activity of MMP-2 and MMP9. However, no significant difference in cell proliferation was detected after silencing TM4SF1. Additionally, knocking down TM4SF1 decreased the formation of lung and liver metastases in orthotopic pancreatic tumor models. Conclusion: Our results demonstrate that the expression of TM4SF1 is higher in pancreatic cancer tissues and pancreatic cancer cell lines than controls. Knockdown of TM4SF1 inhibited the migration and invasion of pancreatic cancer cells by regulating the expression and activity of MMP-2 and MMP-9, which suggests that TM4SF1 may play a significant role in metastasis in pancreatic cancer.




\section{Cellular Physiology Cell Physiol Biochem 2016;38:740-750 and Biochemistry Published online: July 27, $2016 \quad \begin{aligned} & \text { DOI: 10.1159/000445664 } 2016 \text { The Author(s). Published by S. Karger AG, Basel } \\ & \text { www.karger.com/cpb }\end{aligned}$ \\ Cao et al.: The Expression and Function of TM4SF1 in Pancreatic Cancer}

\section{Introduction}

Pancreatic cancer is one of the leading causes of cancer death worldwide. Pancreatic cancer is characterized by difficulties in early diagnosis, local invasion and rapid progression, which are associated with the poorest overall survival rate among human cancers [1,2]. High invasion and metastasis are the main causes of cancer mortality. At the time of diagnosis, most patients have already lost the opportunity for surgical resection and for effective therapeutic treatment. Therefore, understanding the mechanisms of pancreatic cancer underlying its high propensity for metastasis and developing effective treatments targeting metastasis are needed to improve the quality of life and survival of patients [3-6].

In a previous study, we identified various genes that were overexpressed in pancreatic cancer cells by analyzing microarray-generated expression profiles of pancreatic cancer tissues compared with those of normal pancreatic tissues and chronic pancreatitis tissues [7]. This microarray analysis indicated that transmembrane 4 L6 family member 1 (TM4SF1) was expressed at a high level in pancreatic cancer tissues, suggesting that TM4SF1 may be an important regulator in pancreatic cancer development.

TM4SF1, also known as tumor-associated antigen L6, is overexpressed in epithelial cell cancers and regulates cancer cell motility and invasion. The TM4SF1 gene maps to chromosomal region 3q21-3q25. TM4SF1 is abundantly expressed on the plasma membrane and intracellular vesicles [8]. One study indicated that TM4SF1 was necessary for nanopodia formation and interacted with myosin-10 and $\beta$-actin, which regulated the formation of filopodia during cell polarization and motility [9]. TM4SF1 was also highly expressed in activated endothelial cells (EC), including cultured ECs and ECs lining the blood vessels that carry metastatic cells. After stimulating vascular endothelial growth factor (VEGF)-A or thrombin, TM4SF1 interacted with integrins to mediate angiogenesis [10]. Therefore, TM4SF1 is not only involved in metastasis but also regulates the development of angiogenesis, making it a potential target for anti-angiogenesis and anti-tumor therapy.

Matrix metalloproteinases (MMPs), a group of zinc-dependent endopeptidases, have been extensively studied in cancer cell migration and invasion research and are known to degrade various types of extracellular matrix (ECM) proteins and influence the VEGFmediated development of vasculature and metastasis. From a mechanistic view point, the expression and activity of MMPs is closely related to angiogenesis and metastasis in cancers. Among the MMPs, MMP2 and MMP9 have been identified as markers of metastasis, including pancreatic cancer metastasis. We evaluated the association of TM4SF1 with these two genes in pancreatic cancer metastasis [11-16].

In this study, we demonstrate that TM4SF1 is expressed at a high level in pancreatic cancers and pancreatic cancer cell lines. Silencing TM4SF1 inhibited cancer cell migration and invasion by regulating MMP2 and MMP9 in vitro. In an animal study, cells lacking TM4SF1 had a reduced capability to form pancreatic cancer metastases. These results suggest that TM4SF1 acts as an oncogene in pancreatic cancer and is a major target for its treatment or diagnosis.

\section{Materials and Methods}

Pancreatic tissue samples and cell lines

Slides of paraffin-embedded normal pancreatic tissues, chronic pancreatitis tissues or pancreatic adenocarcinoma tissues were obtained from the Department of Pathology at The University of Texas MD Anderson Cancer Center and Xin Hua Hospital, which is affiliated with Shanghai Jiao Tong University School of Medicine. BxPC-3, Capan-1, Capan-2, MOH, CFPAC-1, HPAF2 and HPAC cell lines were cultured in RPMI 1640 medium with $10 \%$ fetal bovine serum (FBS) at $37^{\circ} \mathrm{C}$ in a humidified $5 \% \mathrm{CO}_{2}$ atmosphere incubator. HS766T, PNS1, Panc-48, Panc-3, Panc-28, MIA PaCa-2, PANC-1, AsPC-1, L3.6pl and SU.86.86 cell lines were cultured in Dulbecco's modified Eagle's medium. Human pancreatic duct epithelial (HPDE) cells provided by Dr. Tsao (University of Toronto) were cultured in keratinocyte serum-free medium. 


\section{Cellular Physiology Cell Physiol Biochem 2016;38:740-750

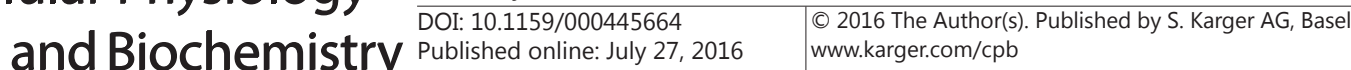 \\ Cao et al.: The Expression and Function of TM4SF1 in Pancreatic Cancer}

Immunohistochemical staining

Unstained $5 \mu \mathrm{m}$ sections of clinical samples were deparaffinized with xylene and rehydrated with ethanol. Antigen retrieval was performed using Borg Decloaker. A primary rabbit polyclonal antibody against TM4SF1 (Sigma) was diluted 1:100 in 5\% normal horse serum/1\% normal goat serum in phosphate-buffered saline (PBS). Tissue slides were developed with a 3, 3'-diaminobenzidine substrate, counterstained with hematoxylin and mounted. The immunohistochemical stains were analyzed using an Olympus microscope. Images of the sections were captured using a chilled charge-coupled device camera (Photometrics) and the Smart Capture software program (Digital Scientific). The staining results were evaluated by a gastrointestinal pathologist (Dr. Huamin Wang, MD Anderson).

Total RNA extraction and quantitative reverse transcription-polymerase chain reaction

Total RNA from pancreatic adenocarcinomas, adjacent normal pancreatic tissues, chronic pancreatitis tissues, pancreatic cancer cell lines, and HPDE was isolated, and the quality of the RNA was determined as previously described [17]. The primers designed for human TM4SF1 were as follows: forward, 5'-GGT TCT TTT CTG GCA TCG TAG GAG GTG-3'; reverse, 5'-CTG GCC GAG GGA ATC AAG ACA TAGTG-3'. The primers designed for human $18 \mathrm{~S}$ ribosomal RNA, which was used as a loading control, were as follows: forward, 5'-GAG CGG TCG GCG TCC CCC AAC TTC-3'; reverse, 5'-GCG CGT GCA GCC CCG GAC ATC TAA-3'. Quantitative reverse transcriptase-polymerase chain reaction (qRT-PCR) was performed using SYBR Premix Ex Taq II (TaKaRa).

\section{Small interfering RNA transfection}

AsPC-1, MIA PaCa-2, and PANC-1 cell lines were transfected with TM4SF1 siRNA (siTM4SF1) in 6-well plates at a final concentration of $10 \mathrm{nmol} / \mathrm{L}$ using the HiPerFect transfection reagent (Qiagen) according to the manufacturer's instructions. The cells were incubated for 48-96 hours.

\section{Cell growth}

Cell growth was analyzed using the MTS reagent (Promega) according to the manufacturer's protocols. AsPC-1, MIA PaCa-2, and PANC-1 cells were transiently transfected with siControl or siTM4SF1 for 24 hours $(n=1000)$ and were then plated on 96 -well plates and grown in $2 \%$ serum-containing medium. Cell numbers were estimated at $0,24,48$, and 72 hours by adding MTS to the wells 1 hour before photometric analysis, as previously described [18].

\section{Cell migration and invasion}

To study cell migration and invasion, Transwell Polycarbonate Membrane Inserts (Corning) and Biocoat Matrigel invasion chambers (BD Biosciences) were used. Briefly, pancreatic cancer cells $\left(2 \times 10^{5}\right)$ transiently transfected with siControl or siTM4SF1 for 48 hours were suspended in $100 \mu \mathrm{L}$ of serumfree media and added to the upper chambers, and 2\% serum-containing medium was added to the lower chambers. The cells were allowed to invade the membrane for 24 hours. The invading cells were analyzed as previously described [18].

\section{Western blotting analysis}

Whole cell lysates were extracted with RIPA buffer for $20 \mathrm{~min}$. The total protein concentration was determined using a BCA protein assay kit. Extracts containing $50 \mu$ g of protein were electrophoresed via 10\% SDS-polyacrylamide gel electrophoresis and transferred onto polyvinylidene difluoride (PVDF) membranes. The membranes were incubated with rabbit anti-TM4SF1 (Abcam, 1:2000 dilution), rabbit anti-MMP2 (Santa Cruz Biotechnology, 1:500 dilution) and rabbit anti-MMP9 (Abcam, 1:500 dilution) overnight at $4^{\circ} \mathrm{C}$, followed by incubation with a horseradish peroxidase-conjugated goat anti-rabbit IgG antibody for 2 hours at room temperature. The signals were detected using an ECL kit (Millipore) according to the manufacturer's instruction.

\section{Gelatin zymography}

After transfection, the medium was changed to serum-free RPMI 1640 or DMEM. The cells were cultured for 24 hours, and the conditioned media were collected. The media were electrophoresed on $10 \%$ precast polyacrylamide gels containing $0.1 \%$ gelatin (Sigma). The enzymatic activity of MMP-2 and MMP-9 was measured using a gelatin zymography kit (Life Technology) according to the manufacturer's protocol. 


\section{Cellular Physiology Cell Physiol Biochem 2016;38:740-750 \begin{tabular}{l|l} 
and Biochemistry Published online: July 27, 2016 & $\begin{array}{l}\text { (c) } 2016 \text { The Author(s). Published by S. Karger AG, Basel } \\
\text { www.karger.com/cpb }\end{array}$
\end{tabular} \\ Cao et al.: The Expression and Function of TM4SF1 in Pancreatic Cancer}

Lentivirus-mediated short hairpin RNA knockdown of TM4SF1 expression

Lentiviral vectors containing TM4SF1 shRNA or control shRNA (Open Biosystems) were cotransfected into $293 \mathrm{~T}$ cells with packaging vectors as previously described. For lentivirus infection, pancreatic cancer cells were seeded in 6-well plates and infected with shTM4SF1- or shControl-expressing virions. Stable pancreatic cancer cell clones expressing the above shRNAs were selected and maintained in medium containing $4 \mu \mathrm{g} / \mathrm{ml}$ puromycin according to the manufacturer's instructions and were screened by quantitative RT-PCR as previously described [13].

\section{Animal studies}

For in vivo tumor experiments, 5-week-old male athymic nude nu/nu mice were divided into shControl and shTM4SF1 groups, with seven mice each. TM4SF1 was knocked down by lentiviral transfection in MIA PaCa-2 cell lines, and stable shRNA-expressing clones were selected. Stably transfected cells or control cells were injected into the pancreases of mice. The tumor sizes were recorded weekly using bioluminescence imaging. Six weeks after the injection, the mice were sacrificed, and each pancreas was removed. The weight of the tumors was recorded. The liver and lungs were inspected for metastases using bioluminescence imaging and Living Image Software.

Statistical analysis

The data were analyzed with SPSS 19.0 statistical software. Experimental data are presented as the means from independent experiments. Statistically significant differences were determined using Dunnett's multiple comparison test, a Mann-Whitney U test and Kruskal-Wallis test or a two-tailed unpaired Student's t-test. A P-value less than 0.05 was considered significant.

\section{Results}

TM4SF1 is overexpressed in pancreatic tumors and cancer cell lines

To identify the specific cells expressing TM4SF1 in the present study, we conducted immunohistochemical staining of pancreatic tissues. We detected faint expression of TM4SF1 in normal pancreatic ducts but not in acinar cells or islets (Fig. 1A). In pancreatic tumors, TM4SF1 expression was high. These data confirmed that TM4SF1 is highly expressed in the neoplastic cells of pancreatic adenocarcinomas [19]. We used quantitative RT-PCR to compare the mRNA levels of TM4SF1 in pancreatic tumor, normal pancreatic tissue, and chronic pancreatitis tissue samples (Fig. 1B). TM4SF1 mRNA expression was 5- to 10- fold higher $(\mathrm{P}<0.05)$ in pancreatic tumors than in the other tissues. We further investigated TM4SF1 mRNA expression in 18 pancreatic cancer cell lines and HPDE cells. The mRNA expression of TM4SF1 in all the pancreatic cancer cell lines was higher than that in HPDE cells $(\mathrm{P}<0.05$, Fig. 1C).

TM4SF1 expression levels correlate with pancreatic cancer cell migration, invasion, and survival rates in vitro

To investigate the functional role of TM4SF1 in pancreatic cancer cells, we transiently transfected AsPC-1, MIA PaCa-2, and PANC-1 cells with siControl or siTM4SF1 and confirmed the silencing of TM4SF1 in the cells using qRT-PCR. The assay showed that the mRNA expression of TM4SF1 decreased by more than 70\% with siTM4SF1 (Fig. 2A). We then analyzed the transfected cells for changes in proliferation, migration and invasion in vitro. The proliferation of TM4SF1-silenced cells over 72 hours was not significantly different compared to the siControl-transfected cells based on the MTS assay (P $>0.05$, Fig. 2B). However, silencing of TM4SF1 markedly reduced the migration and invasion of pancreatic cancer cells (Fig. 3A and 3B). The mean reduction in the migration of AsPC-1, MIA PaCa2 , and PANC- 1 cells was $63.65 \%, 61.77 \%$ and $69.33 \%$, respectively. The mean reduction in the invasion of AsPC-1, MIA PaCa-2, and PANC- 1 cells was $64.74 \%, 66.41 \%$ and $57.83 \%$ $(\mathrm{P}<0.05)$. 
Fig. 1. TM4SF1 was overexpressed in pancreatic tumors and cancer cell lines. (A) Immunohistochemical analysis showing the location of TM4SF1 in samples of pancreatic adenocarcinoma and adjacent benign pancreatic tissue at a magnification of $\times 200$. The normal tissue samples exhibited only slight staining for TM4SF1. In contrast, the adenocarcinoma sample showed strong staining. (B) qRT-PCR analysis of the TM4SF1 mRNA expression in normal pancreatic tissue, chronic pancreatitis tissue and pancreatic adenocarcinoma

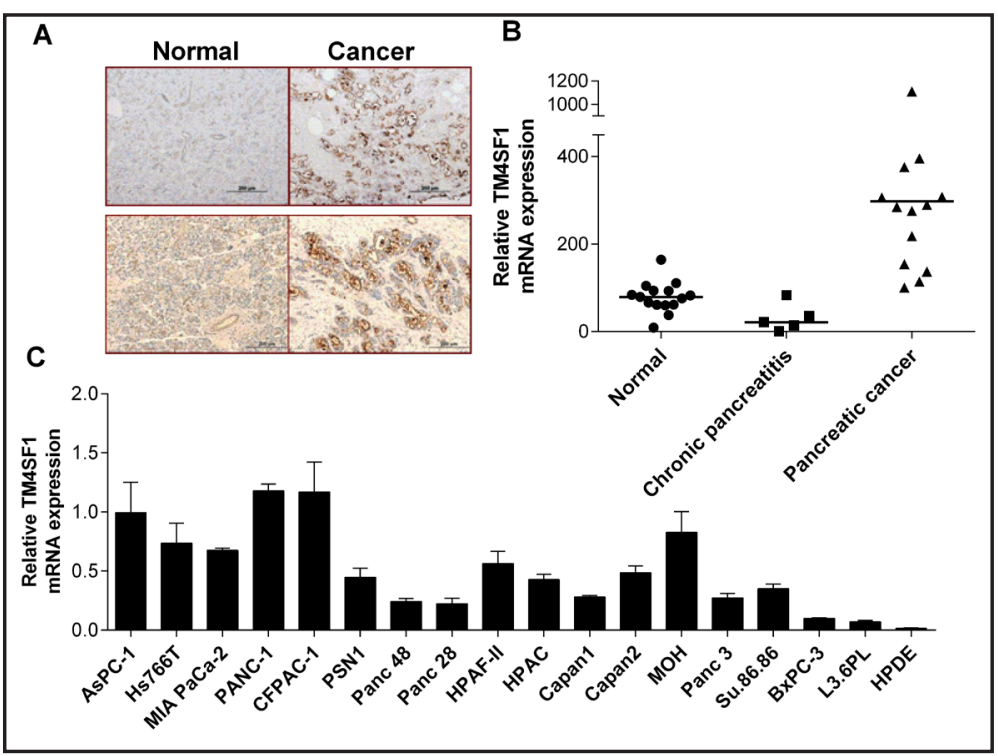
samples. The expression of TM4SF1 was higher in pancreatic adenocarcinomas than normal pancreatic and chronic pancreatitis tissues. (C) the mRNA expression of TM4SF1 was higher in the cancer cell lines than in HPDE cells.

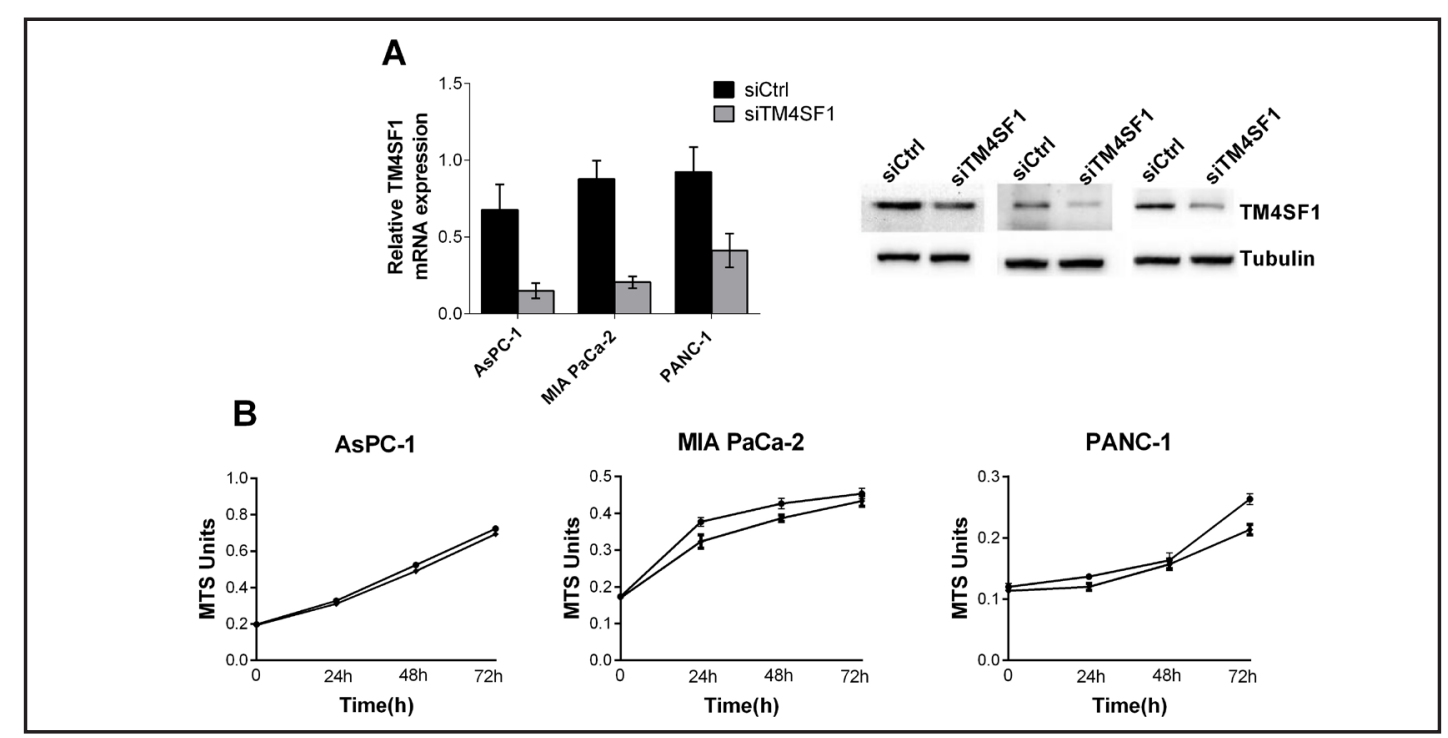

Fig. 2. In vitro proliferation of AsPC-1, MIA PaCa-2, and PANC-1 cells was not significantly altered after transfection with siTM4SF1. (A) qRT-PCR analysis of mRNA expression after silencing TM4SF1 expression in AsPC-1, MIA PaCa-2 and PANC-1 cells. (B) MTS assays showed that the cell growth rates of siControl-transfected cells and siTM4SF1-transfected cells were not significantly different. ${ }^{*} \mathrm{P}<0.05$ vs control group.

\section{TM4SF1 mediates MMP2 and MMP9 expression and activation}

Previous studies have demonstrated that MMPs are major ECM-degrading enzymes and that the high expression and activation of MMPs may contribute to the development of cancer metastasis [20]. Thus, we determined whether TM4SF1 could lead to increased expression and activity of MMPs during the process of metastasis in pancreatic cancer. Compared with the siControl groups, the siTM4SF1 groups showed significantly down-regulated mRNA and protein levels of MMP2 and MMP9 in pancreatic cancer cells ( $<<0.05$, Fig. 4A and 4B). In addition, the results of gelatin zymography indicated that the secretion of MMP2 and MMP9 was significantly decreased in TM4SF1 siRNA-transfected cells compared to control siRNAtransfected cells ( $\mathrm{P}<0.05$, Fig. 4C and 4D). 


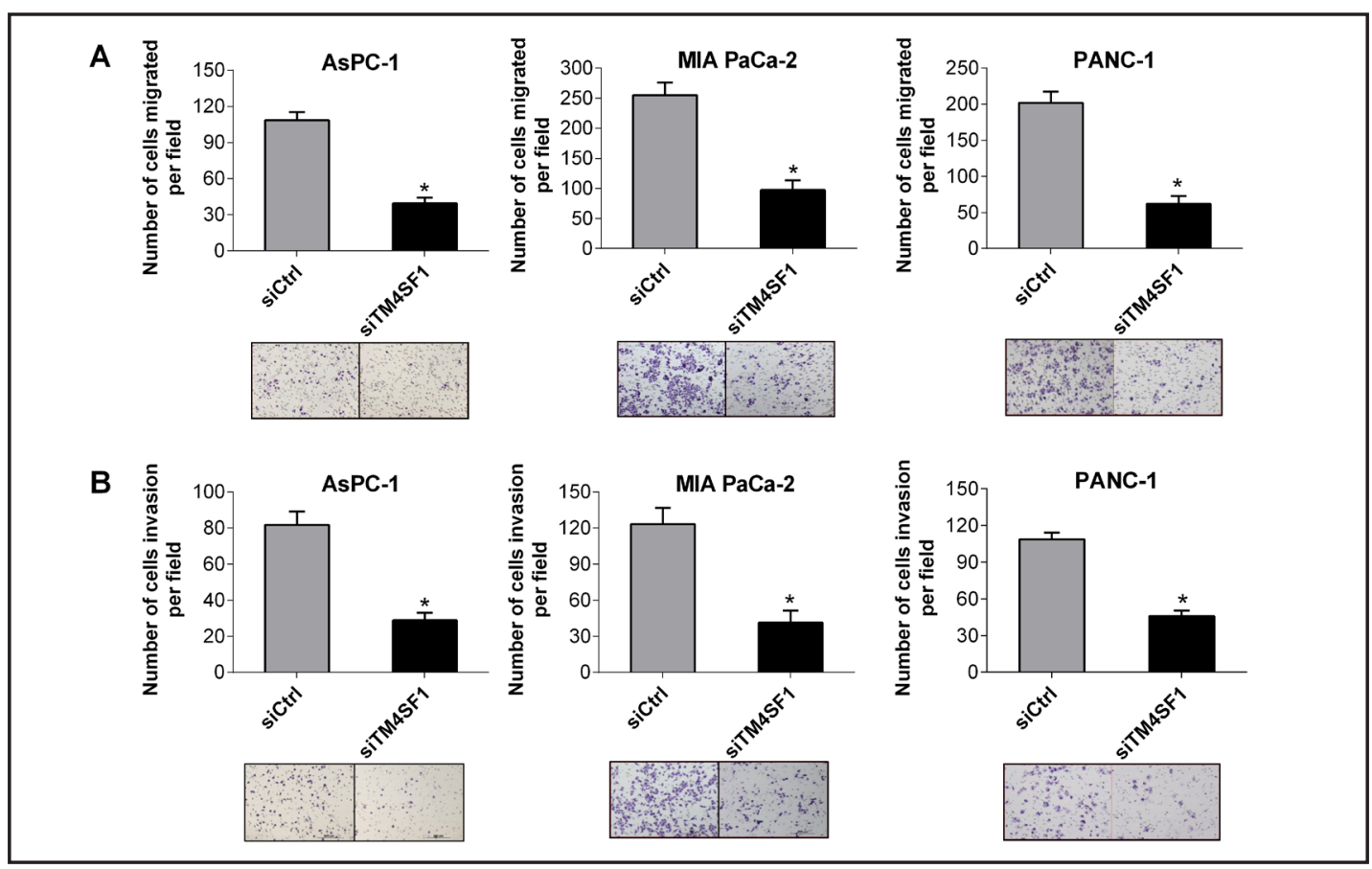

Fig. 3. Pancreatic cancer cell migration and invasion were decreased following transient silencing of TM4SF1. (A) Effect of siRNA silencing of TM4SF1 on the migration of AsPC-1, MIA PaCa-2, and PANC-1 cells. After transiently transfecting cells with siControl or siTM4SF1, cells were added to the upper compartment of a migration or invasion chamber, and the number of cells invading the lower chamber was estimated in eight random fields at $\times 100$ magnification after 24 hours. The rate of migration of cells with transiently silenced TM4SF1 expression was markedly reduced. (B) siRNA silencing of TM4SF1 expression on the invasion of AsPC-1, MIA PaCa-2, and PANC- 1 cells. ${ }^{*} \mathrm{P}<0.05$ versus control.

TM4SF1 silencing reduces metastasis of pancreatic tumors in vivo

To further elucidate the role of TM4SF1 in pancreatic cancer, we transfected MIA PaCa-2 cell lines with shRNA constructs to stably knock down the expression of TM4SF1. We confirmed shRNA silencing using qRT-PCR (Fig. 5A) and determined that the mRNA expression of TM4SF1 decreased by approximately 90\% with shTM4SF1-1. After injecting MIA PaCa-2 cells stably expressing shControl or shTM4SF1-1 into nude mice, orthotopic tumors developed (Fig. 5B). The tumor weights of the shTM4SF1 group were not significantly different than those of the shControl group. We also evaluated pancreatic tumor metastases to the liver and lung. TM4SF1 silencing reduced the incidence of metastasis to both sites (lungs, $\mathrm{P}=0.007$ and liver, $\mathrm{P}=0.0265$ [Mann-Whitney $\mathrm{U}$ test]) (Fig. 5D).

\section{Discussion}

The morbidity and mortality of pancreatic cancer is increasing rapidly and is considered to be a common cause of cancer-related death. The characteristics of pancreatic cancer include local invasion, early metastasis and chemoresistance. Because most patients are diagnosed at advanced stages, the successful surgical resection rate and the 5-year survival rate are low. Gemcitabine has been used as a first-line chemotherapy drug for pancreatic cancer, but the survival time of patients is still no more than 6 months for metastatic disease and 9-12 months for locally advanced disease. To improve patients' survival, a better understanding of the molecular mechanisms that control pancreatic cancer metastasis is urgently needed [21-24]. 
Fig. 4. Silencing of TM4SF1 decreased the expression and activity of MMP2 and MMP9. (A) the mRNA expression of MMP2 and MMP9 measured by qRT-PCR in AsPC-1 and PANC-1 cells after different treatments. (B) Western blot analysis of the protein expression of MMP2 and MMP9 after silencing TM4SF1 compared with a negative control. (C) Gelatin zymography of activated MMP2 and MMP9 in the conditioned media of siControl-transfected and siTM4SF1-transfected cells. (D) densitometric analysis of MMP2 and MMP9 enzymatic activity. $* \mathrm{P}<0.05$ vs control.
A

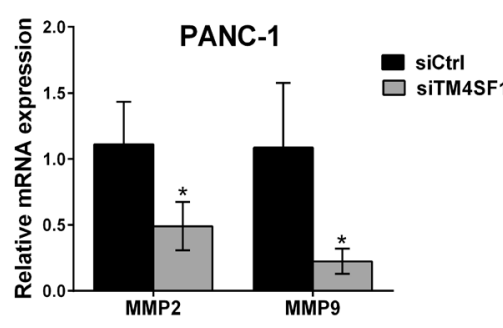

B
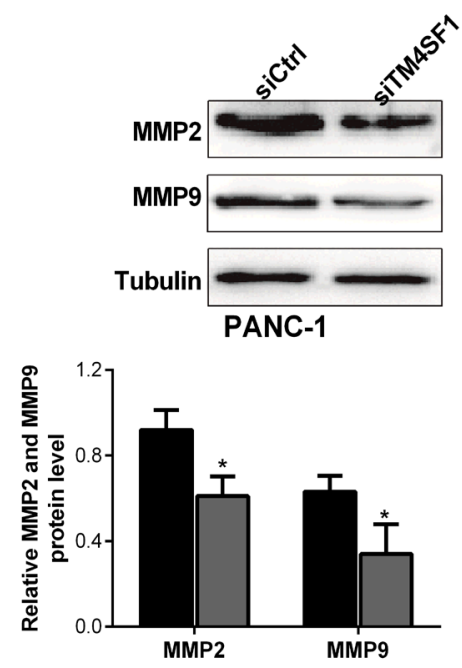

C

PANC-1

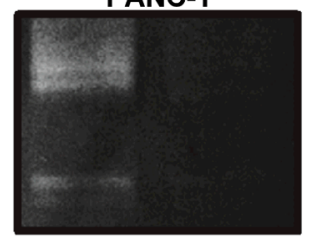

D
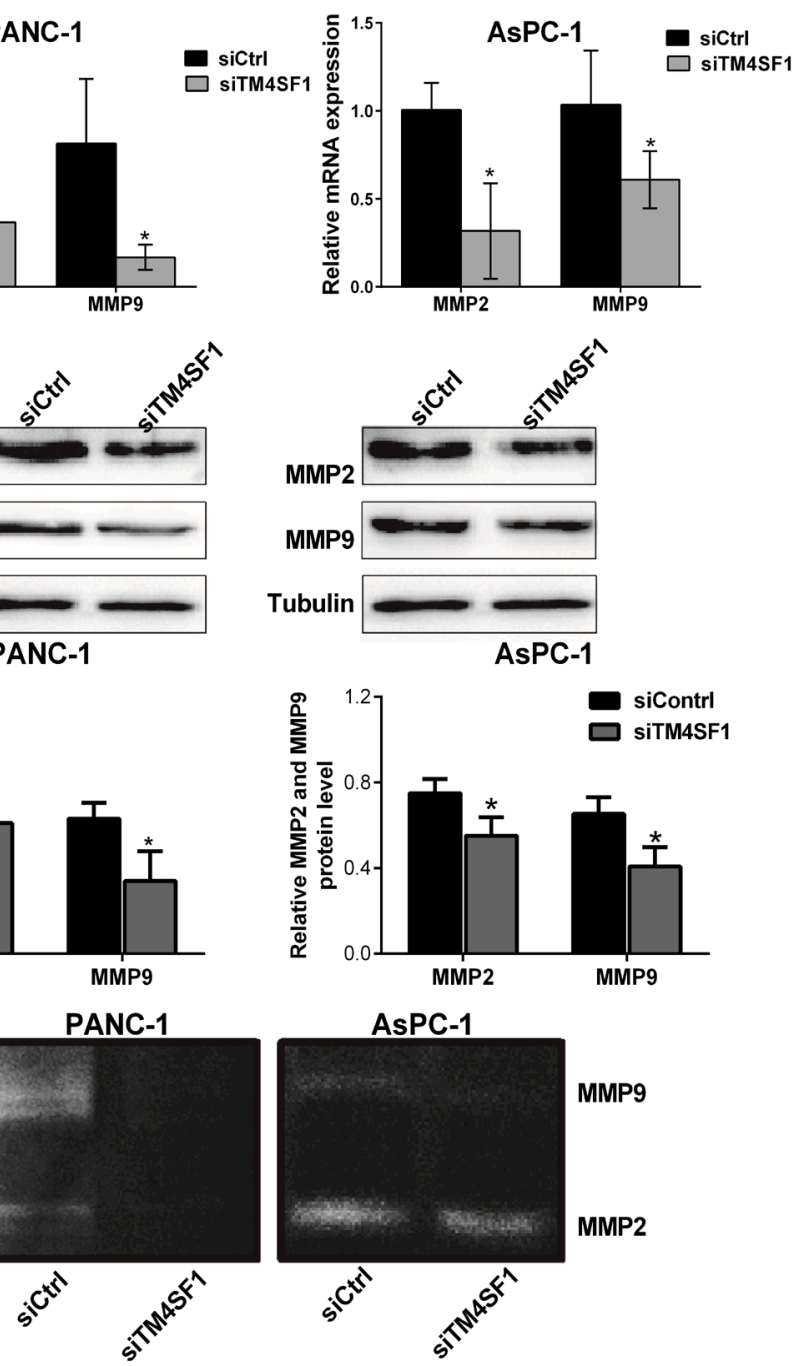

AsPC-1
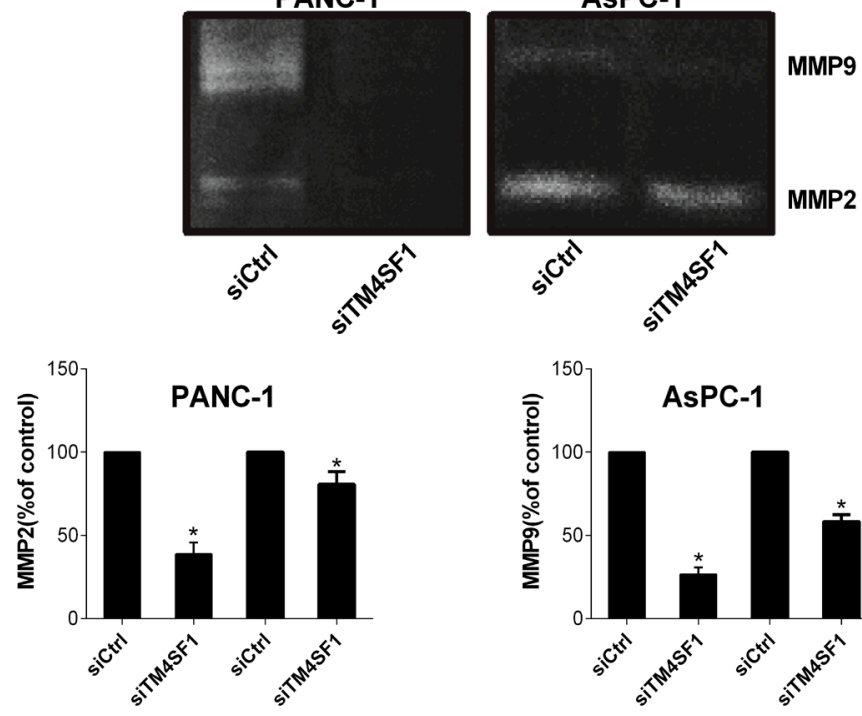

In previous studies, TM4SF1, a membrane-associated glycoprotein, has been found to be overexpressed in various human malignant tumors and is considered to be a major mediator of cancer metastasis. TM4SF1 was expressed in human lung, breast, colon, renal, prostate and ovarian cancers $[25,26]$. In squamous cell lung cancer, the expression of TM4SF1 promoted invasion and was significantly correlated with an early postoperative relapse and shorter survival. Coimmunoprecipitation analysis showed that CD13 was associated with TM4SF1 and formed a complex on lung cancer cells that enhanced cell migration [27]. For the first time, Allioli demonstrated that TM4SF1 expression was higher in prostate cancer tissues than benign prostatic tissues and that TM4SF1directly targeted the androgen receptor to 


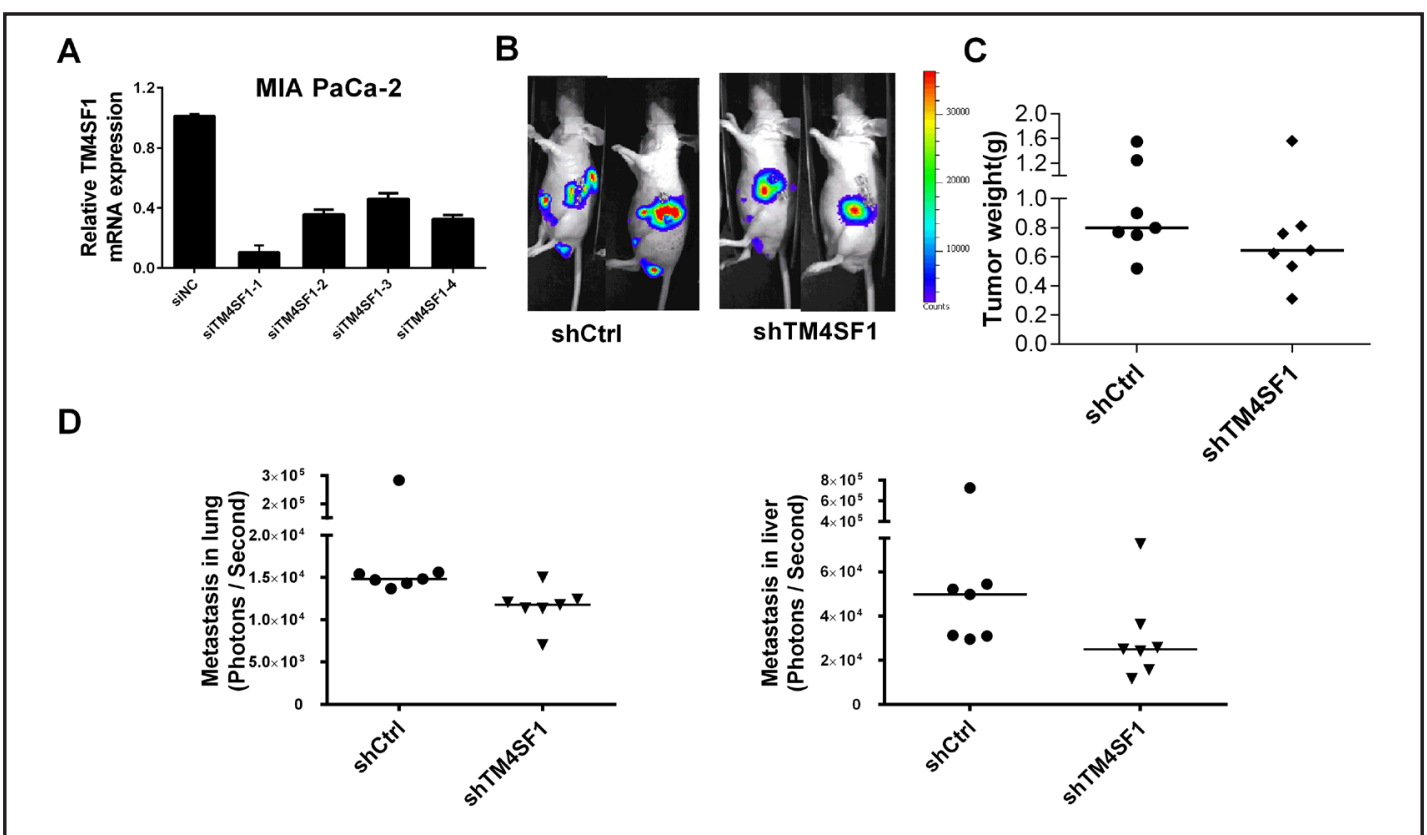

Fig. 5. Reduction in pancreatic cell metastasis in vivo after TM4SF1 silencing. (A) the mRNA expression of TM4SF1 in MIA PaCa-2 cells after knocking down TM4SF1 using shRNA. (B) growth of orthotopic tumors using MIA PaCa-2 cells that stably expressed shControl or shTM4SF1. (C) the tumor weights of the shControl and shTM4SF1 groups were not significantly different. (D) the incidences of metastasis to the lung and liver were calculated. TM4SF1 silencing significantly reduced the incidence of lung and liver metastases. ${ }^{*} \mathrm{P}<0.05$ versus control by Mann-Whitney $\mathrm{U}$ test, $\mathrm{P}=0.007$ for lung metastasis, $\mathrm{P}=0.0265$ for liver metastasis (for seven animals).

promote cell migration [28]. Using two highly motile breast cancer cell lines, TM4SF1 was found to be associated with tetraspanin-enriched microdomains (TERM) and regulate the surface expression of CD63 and CD82. They also found that TM4SF1 was ubiquitylated and that ubiquitylation was essential for cell migration [8]. Additionally, the nanopodia were long and thin, and the F-actin-negative membrane projections had TM4SF1 clusters in TM4SF1enriched microdomains (TMED) in EC and cancer cells. As a molecular organizer, TM4SF1 interacted with myosin-10 and $\beta$-actin and was involved in nanopodia formation and cell polarization and migration $[9,29]$.

The role of TM4SF1 in cancer angiogenesis and its potential as a therapeutic target in cancers have been demonstrated. In an in vitro study, endothelial cells lost the ability to polarize, migrate and proliferate after silencing TM4SF1. TM4SF1 was highly expressed by the endothelial lining of angiogenic blood vessels and affected the capacity of endothelial cells to form new blood vessels in vivo. Due to its location on the cellular surface of tumorassociated endothelium, TM4SF1 may be a promising therapeutic target in an antibodydrug conjugate (ADC) approach. The mouse anti-human TM4SF1 monoclonal antibody 8G4 attached to microtubules by binding myosin-X and was transported through the cytoplasm. This antibody lost its attachment with the membranes when it passed through the nuclear pores and entered the nucleoplasm. These results demonstrate that TM4SF1 is an important target in ADC cancer therapy [30-32].

Overall, we suggest that TM4SF1 is an important molecular target for metastasis and treatment of pancreatic cancer. In pancreatic cancer cell lines, miR-141 down-regulated the expression of TM4SF1 to inhibit cell migration and invasion by directly targeting the 3'-untranslated region of the mRNA of this gene [19]. Nevertheless, the molecular mechanisms of TM4SF1 in pancreatic cancer metastasis remain unclear. The aim of this study was to evaluate the carcinogenic role of TM4SF1 and determine its molecular mechanism of 


\section{Cellular Physiology Cell Physiol Biochem 2016;38:740-750 \begin{tabular}{lll} 
DOI: 10.1159/000445664 & $\begin{array}{l}\text { O 2016 The Author(s). Published by S. Karger AG, Basel } \\
\text { www.karger.com/cpb }\end{array}$ \\
\hline and Biochemistry
\end{tabular} \\ Cao et al.: The Expression and Function of TM4SF1 in Pancreatic Cancer}

action in pancreatic cancer. Our study showed that the expression of TM4SF1 was highly increased in pancreatic cancer tissues and pancreatic cancer cell lines. Surprisingly, we did not observe any effect of TM4SF1 on the proliferation of pancreatic cancer cells in vitro and in vivo. However, we found that silencing TM4SF1 reduced pancreatic cancer cell invasion and metastasis in vivo. These data suggest that TM4SF1 overexpression is common in pancreatic cancer and may be associated with cancer metastasis.

Previous studies have also demonstrated that degradation of extracellular matrix components is an important step in metastasis in cancers by promoting cancer cells to break through the basement membrane and metastasize to distant tissues [33]. It has generally been shown that MMP2 and MMP9 are bio-markers for cancer invasion and metastasis because they degrade ECM components in pancreatic cancer. MMPs also regulated the tumor microenvironment, which affected cell growth, inflammation or angiogenesis [3438]. Furthermore, we demonstrated that down-regulation of TM4SF1 led to suppression of the mRNA and protein levels of MMP2 and MMP9, which indicated that TM4SF1 might affect cancer cell migration and invasion by enhancing the expression of MMP2 and MMP9. In addition, inhibition of TM4SF1 reduced the secretion of MMP2 and MMP9.

These results suggest that TM4SF1 induced pancreatic cancer metastasis through MMP2 and MMP9 regulation. However, the mechanism underlying the down-regulation of MMP2 and MMP9 after silencing TM4SF1, which affects cancer cell migration and invasion, remains to be explored.

Based on the above results, we conclude that TM4SF1 is overexpressed in pancreatic cancer and can influence cancer cell migration and invasion via MMP2 and MMP9 regulation and may provide a novel therapeutic target for the treatment of pancreatic cancer.

\section{Acknowledgments}

The study was supported by: NIH-DK05207 (to C.D.Logsdon), Cancer Center Support Core grant CA016672 (to UT M.D. Anderson Cancer Center), the Lockton Endowment (to C.D.Logsdon), National Natural Science Foundation of China-81301826 (to Jia Cao) and National Natural Science Foundation of China-81472844(to Lei-ming Xu).

\section{Disclosure Statement}

The authors declare that they have no competing interests.

\section{References}

1 Sun XJ, Liu BY, Yan S, Jiang TH, Cheng HQ, Jiang HS, Cao Y, Mao AW: MicroRNA-29a Promotes Pancreatic Cancer Growth by Inhibiting Tristetraprolin. Cell Physiol Biochem 2015;37:707-718.

2 Yu T, Wang YT, Chen P, Li YH, Chen YX, Zeng H, Yu AM, Huang M, Bi HC: Effects of nicotinamide $\mathrm{N}$-methyltransferase on PANC-1 cells proliferation, metastatic potential and survival under metabolic stress. Cell Physiol Biochem 2015;35:710-721.

3 Siegel RL, Miller KD, Jemal A: Cancer statistics, 2015. CA Cancer J Clin 2015;65:5-29.

4 Cartwright T, Richards DA, Boehm KA: Cancer of the pancreas: are we making progress? A review of studies in the US Oncology Research Network. Cancer Control 2008;15:308-313.

5 Brenner H, Gondos A, Arndt V: Recent major progress in long-term cancer patient survival disclosed by modeled period analysis. J Clin Oncol 2007;25:3274-3280.

6 Chua YJ, Cunningham D: Adjuvant treatment for resectable pancreatic cancer. J Clin Oncol 2005;23:4532-4537. 


\section{Cellular Physiology Cell Physiol Biochem 2016;38:740-750 \begin{tabular}{l|l} 
DOI: 10.1159/000445664 & $\begin{array}{l}\text { O 2016 The Author(s). Published by S. Karger AG, Basel } \\
\text { wwww.karger.com/cpb }\end{array}$
\end{tabular} \\ Cao et al.: The Expression and Function of TM4SF1 in Pancreatic Cancer}

7 Logsdon CD, Simeone DM, Binkley C, Arumugam T, Greenson JK, Giordano TJ, Misek DE, Kuick R, Hanash S: Molecular profiling of pancreatic adenocarcinoma and chronic pancreatitis identifies multiple genes differentially regulated in pancreatic cancer. Cancer Res 2003;63:2649-2657.

8 Lekishvili T, Fromm E, Mujoomdar M, Berditchevski F: The tumour-associated antigen L6 (L6-Ag) is recruited to the tetraspanin-enriched microdomains: implication for tumour cell motility. J Cell Sci 2008;121:685-694.

9 Zukauskas A, Merley A, Li D, Ang LH, Sciuto TE, Salman S, Dvorak AM, Dvorak HF, Jaminet SC: TM4SF1: a tetraspanin-like protein necessary for nanopodia formation and endothelial cell migration. Angiogenesis 2011;14:345-354.

10 Shih SC, Zukauskas A, Li D, Liu G, Ang LH, Nagy JA, Brown LF, Dvorak HF: The L6 protein TM4SF1 is critical for endothelial cell function and tumor angiogenesis. Cancer Res 2009;69:3272-3277.

11 Deryugina EI, Quigley JP: Tumor angiogenesis: MMP-mediated induction of intravasation- and metastasis-sustaining neovasculature. Matrix Biol 2015;44-46:94-112.

12 Singh D, Srivastava SK, Chaudhuri TK, Upadhyay G: Multifaceted role of matrix metalloproteinases (MMPs). Front Mol Biosci 2015;2:19.

13 Lin CW, Hou WC, Shen SC, Juan SH, Ko CH, Wang LM, Chen YC: Quercetin inhibition of tumor invasion via suppressing PKC delta/ERK/AP-1-dependent matrix metalloproteinase-9 activation in breast carcinoma cells. Carcinogenesis 2008;29:1807-1815.

14 Shen B, Zheng MQ, Lu JW, Jiang Q, Wang TH, Huang XE: CXCL12-CXCR4 promotes proliferation and invasion of pancreatic cancer cells. Asian Pac J Cancer Prev 2013;14:5403-5408.

15 Zhang W, Zhang T, Lou Y, Yan B, Cui S, Jiang L, Han B: Placental growth factor promotes metastases of non-small cell lung cancer through MMP9. Cell Physiol Biochem 2015;37:1210-1218.

16 Wang R, Ke ZF, Wang F, Zhang WH, Wang YF, Li SH, Wang LT: GOLPH3 overexpression is closely correlated with poor prognosis in human non-small cell lung cancer and mediates its metastasis through upregulating MMP-2 and MMP-9. Cell Physiol Biochem 2015;35:969-982.

17 Qin XF, An DS, Chen IS, Baltimore D: Inhibiting HIV-1 infection in human T cells by lentiviral-mediated delivery of small interfering RNA against CCR5. Proc Natl Acad Sci U S A 2003;100:183-188.

18 Ramachandran V, Arumugam T, Hwang RF, Greenson JK, Simeone DM, Logsdon CD: Adrenomedullin is expressed in pancreatic cancer and stimulates cell proliferation and invasion in an autocrine manner via the adrenomedullin receptor, ADMR. Cancer Res 2007;67:2666-2675.

19 Xu L, Li Q, Xu D, Wang Q, An Y, Du Q, Zhang J, Zhu Y, Miao Y: hsa-miR-141 downregulates TM4SF1 to inhibit pancreatic cancer cell invasion and migration. Int J Oncol 2014;44:459-466.

20 Haage A, Schneider IC: Cellular contractility and extracellular matrix stiffness regulate matrix metalloproteinase activity in pancreatic cancer cells. FASEB J 2014;28:3589-3599.

21 Goral V: Pancreatic Cancer: Pathogenesis and Diagnosis. Asian Pac J Cancer Prev 2015;16:5619-5624.

22 Cid-Arregui A, Juarez V: Perspectives in the treatment of pancreatic adenocarcinoma. World J Gastroenterol 2015;21:9297-9316.

23 Berlin JD, Catalano P, Thomas JP, Kugler JW, Haller DG, Benson AB, 3rd: Phase III study of gemcitabine in combination with fluorouracil versus gemcitabine alone in patients with advanced pancreatic carcinoma: Eastern Cooperative Oncology Group Trial E2297. J Clin Oncol 2002;20:3270-3275.

24 Burris HA, 3rd, Moore MJ, Andersen J, Green MR, Rothenberg ML, Modiano MR, Cripps MC, Portenoy RK, Storniolo AM, Tarassoff P, Nelson R, Dorr FA, Stephens CD, Von Hoff DD: Improvements in survival and clinical benefit with gemcitabine as first-line therapy for patients with advanced pancreas cancer: a randomized trial. J Clin Oncol 1997;15:2403-2413.

25 Hellstrom I, Horn D, Linsley P, Brown JP, Brankovan V, Hellstrom KE: Monoclonal mouse antibodies raised against human lung carcinoma. Cancer Res 1986;46:3917-3923.

26 Kao YR, Shih JY, Wen WC, Ko YP, Chen BM, Chan YL, Chu YW, Yang PC, Wu CW, Roffler SR: Tumorassociated antigen L6 and the invasion of human lung cancer cells. Clin Cancer Res 2003;9:28072816.

27 Chang YW, Chen SC, Cheng EC, Ko YP, Lin YC, Kao YR, Tsay YG, Yang PC, Wu CW, Roffler SR: CD13 (aminopeptidase N) can associate with tumor-associated antigen L6 and enhance the motility of human lung cancer cells. Int J Cancer 2005;116:243-252. 


\section{Cellular Physiology Cell Physiol Biochem 2016;38:740-750 \begin{tabular}{ll|l} 
DOI: 10.1159/000445664 & $\begin{array}{l}\text { O 2016 The Author(s). Published by S. Karger AG, Basel } \\
\text { www.karger.com/cpb }\end{array}$
\end{tabular} \\ Cao et al.: The Expression and Function of TM4SF1 in Pancreatic Cancer}

28 Allioli N, Vincent S, Vlaeminck-Guillem V, Decaussin-Petrucci M, Ragage F, Ruffion A, Samarut J: TM4SF1, a novel primary androgen receptor target gene over-expressed in human prostate cancer and involved in cell migration. Prostate 2011;71:1239-1250.

29 Lin CI, Lau CY, Li D, Jaminet SC: Nanopodia--thin, fragile membrane projections with roles in cell movement and intercellular interactions. J Vis Exp DOI:10.3791/51320.

30 Lin CI, Merley A, Sciuto TE, Li D, Dvorak AM, Melero-Martin JM, Dvorak HF, Jaminet SC: TM4SF1: a new vascular therapeutic target in cancer. Angiogenesis 2014;17:897-907.

31 Sciuto TE, Merley A, Lin CI, Richardson D, Liu Y, Li D, Dvorak AM, Dvorak HF, Jaminet SC: Intracellular distribution of TM4SF1 and internalization of TM4SF1-antibody complex in vascular endothelial cells. Biochem Biophys Res Commun 2015;465:338-343.

32 Visintin A, Knowlton K, Tyminski E, Lin CI, Zheng X, Marquette K, Jain S, Tchistiakova L, Li D, O'Donnell CJ, Maderna A, Cao X, Dunn R, Snyder WB, Abraham AK, Leal M, Shetty S, Barry A, Zawel L, Coyle AJ, Dvorak HF, Jaminet SC: Novel Anti-TM4SF1 Antibody-Drug Conjugates with Activity against Tumor Cells and Tumor Vasculature. Mol Cancer Ther 2015;14:1868-1876.

33 Egeblad M, Werb Z: New functions for the matrix metalloproteinases in cancer progression. Nat Rev Cancer 2002;2:161-174.

34 Ito H, Duxbury M, Benoit E, Clancy TE, Zinner MJ, Ashley SW, Whang EE: Prostaglandin E2 enhances pancreatic cancer invasiveness through an Ets-1-dependent induction of matrix metalloproteinase-2. Cancer Res 2004;64:7439-7446.

35 Shay G, Lynch CC, Fingleton B: Moving targets: Emerging roles for MMPs in cancer progression and metastasis. Matrix Biol 2015;44-46:200-206.

36 Roy R, Louis G, Loughlin KR, Wiederschain D, Kilroy SM, Lamb CC, Zurakowski D, Moses MA: Tumorspecific urinary matrix metalloproteinase fingerprinting: identification of high molecular weight urinary matrix metalloproteinase species. Clin Cancer Res 2008;14:6610-6617.

37 Ellenrieder V, Alber B, Lacher U, Hendler SF, Menke A, Boeck W, Wagner M, Wilda M, Friess H, Buchler M, Adler G, Gress TM: Role of MT-MMPs and MMP-2 in pancreatic cancer progression. Int J Cancer 2000;85:14-20.

38 Kessenbrock K, Plaks V, Werb Z: Matrix metalloproteinases: regulators of the tumor microenvironment. Cell 2010;141:52-67. 